\title{
Alpha-chain Disease with Pulmonary Manifestations
}

\author{
A FLORIN-CHRISTENSEN, D. DONIACH, P. B. NEWCOMB
}

British Medical fournal, 1974, 2, 413-415

\section{Summary}

A case of alpha-chain disease of the pulmonary type is desscribed in a man presenting with dyspnoea, mottling on chest $x$-ray picture, and a CO-transfer factor of $36 \%$, suggestive of fibrosing alveolitis. The serum IgA consisted entirely of abnormal alpha chains devoid of light chains. This protein had the unusual property of reacting by immunofluorescence with rat mitochondria but not with human issues or with those of other species. Postmortem examination showed enlarged mediastinal lymph nodes with no evidence of malignancy or fibrosing alveolitis.

\section{Introduction}

Heavy-chain disease of the IgA class (alpha-chain) with pulmonary presentation rather than with the more usual intestinal lymphoma has been reported in only three patients (Moroz et al., 1971; Stoop et al., 1971; Faux et al., 1973) since the disease was first discovered by Seligmann et al. (1968). In the present case the diagnosis was made retrospectively on the basis of clinical and postmortem findings after immunochemical analysis of serum specimens taken one and a half years before death. The clinical course is described to emphasize the features which might help to detect future cases during life.

\section{Cast Report}

A 76-year-old shoemaker first presented in October 1971 with a history of increasing dyspnoea since April 1970 not associated with cough, sputum, fever, or symptoms of left ventricular failure. The dyspnoea was severe and limited his walking to 50 yards (45.7 metres). On further questioning he admitted to slight shortness of breath for the past six to eight years. He also had an irritating skin rash which was diagnosed as a dermatitis due to excessive use of phenolated soap.

Past history showed that he had always been in good health, had not suffered from chronic bronchitis, and had not been exposed to industrial pulmonary hazards. He smoked up to seven cigarettes per day. In 1969 he was briefly admitted to hospital after an attack of vomiting with coffee grounds. A barium meal field showed nothing abnormal, and a chest $x$-ray picture showed no abnormality except for a bullous area at the right apex. His only other admission had been for hernia repair in 1961 .

On examination his pulse rate was normal and blood pressure was $160 / 90 \mathrm{~mm} \mathrm{Hg}$. There were fine crackling crepitations over both lung fields but the heart sounds were normal and there was no ankle oedema. The liver edge was felt $2 \mathrm{~cm}$ below the costal margin and the spleen and lymph nodes were impalpable.

On investigation $\mathrm{Hb}$ was $13.3 \mathrm{~g} / 100 \mathrm{ml}$; W.B.C. was $10,000 /$ $\mathrm{mm}^{3}$, consisting of $80 \%$ neutrophils, $15 \%$ lymphocytes, $4 \%$ monocytes, and $1 \%$ eosinophils; E.S.R. was $58 \mathrm{~mm}$ (1 hour

\footnotetext{
Department of Immunology, Middlesex Hospital Medical School, London W1P 9PG

A. FLORIN-CHRISTENSEN, M.D., Wellcome Research Fellow in D. DONIACH, M.D., F.R.C.P., Reader in Immunopathology

Hackney Hospital, London E9

P. B. NEWCOMB, M.D., F.R.C.P., Consultant Physician
}

Westergren). Platelets were normal. A chest $x$-ray picture (fig. 1 ) showed "diffuse interstitial pulmonary fibrosis and left pleural effusion." Lung function tests gave normal results for volumes and vital capacity, but the CO-transfer factor was 8.3 for a predicted value of $23 \mathrm{ml} / \mathrm{min} / \mathrm{mm} \mathrm{Hg}(36 \%)$.

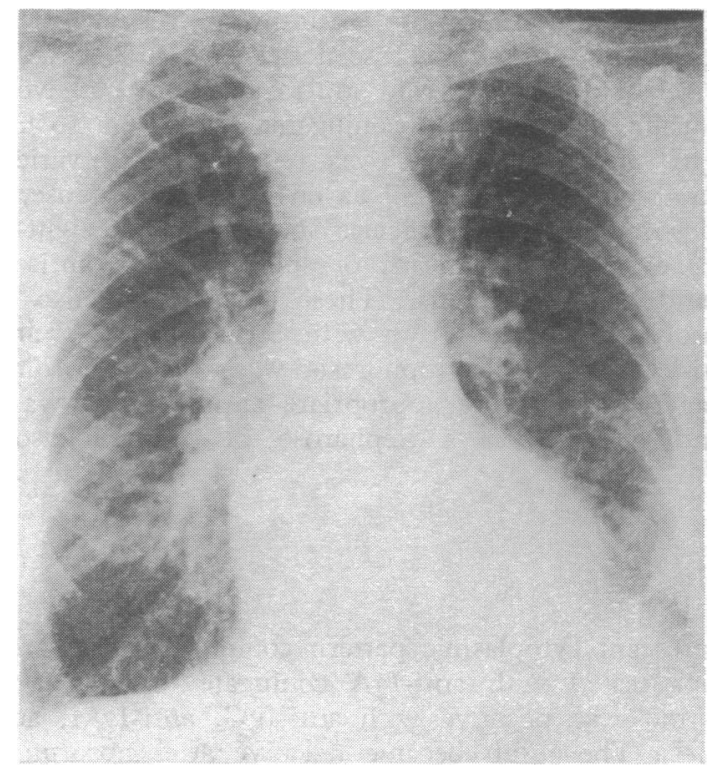

FIG. 1 -Chest $x$-ray picture obtained October 1971.

On the suspicion of idiopathic fibrosing alveolitis, serum proteins were examined: total protein was $8 \mathrm{~g} / 100 \mathrm{ml}$-albumin $4.2 \mathrm{~g} / 100 \mathrm{ml}$ and globulin $3.8 \mathrm{~g} / 100 \mathrm{ml}$. Serum electrophoresis showed an abnormal band between $\beta$ and $\gamma$ (fig. 2). Serum IgG was $900 \mathrm{mg}$, IgA $460 \mathrm{mg}$, and $\mathrm{IgM} 84 \mathrm{mg} / 100 \mathrm{ml}$. There was a 2+ proteinuria which increased to $4+$ in January 1972. Autoantibody tests: latex F11 was positive to $1 / 40$; antinuclear antibody was positive to $1 / 20$; L.E. cells were absent. The serum also gave a cytoplasmic tissue fluorescence which was difficult to interpret at that time. Liver function tests: alkaline phosphatase $10.6 \mathrm{~K}$.A. units/ml, SGPT $7 \mathrm{U} / \mathrm{ml}$, SGOT $15 \mathrm{U} / \mathrm{ml}$, bilirubin $0.5 \mathrm{mg} / 100$ $\mathrm{ml}$, and cholesterol $160 \mathrm{mg} / 100 \mathrm{ml}$. Bromsulphalein retention was $10.3 \%$ at 45 minutes though liver biopsy showed no abnormality. E.C.G. suggested right ventricular preponderance.

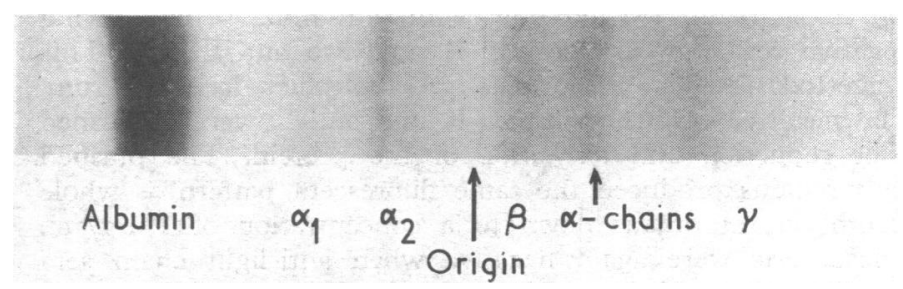

FIG. 2-Serum electrophoresis on cellulose acetate showing abnormal band between $\beta$ and $\gamma$ globulins.

These results strengthened the suspicion of an obscure autoimmune lung condition but no facilities were available for further analysis of the abnormal electrophoretic band, and alpha-chain disease was not suspected since the cases described at that time were in subjects of Mediterranean origin with severe malabsorption syndromes. The patient was transferred to a geriatric unit and died in May 1973. 
Postmortem examination showed patchy haemorrhagic areas in the trachea, bilteral pleural adhesions, and a purulent exudate at the left lung base. The mediastinal nodes were enlarged. Liver and spleen were macroscopically normal. Both kidneys were of a normal size and colour and the capsules stripped easily. Histological reports were available only on lung and kidney. There was no evidence of fibrosing alveolitis, the histological appearances of the kidney were normal, and the immediate cause of death was considered to be basal bronchopneumonia.

\section{Immunological Studies}

\section{METHODS}

Immunological studies of the serum were resumed for research purposes. Immunofluorescence was first done on composite blocks of human thyroid and stomach and rat liver and kidney, using specific FITC conjugates of antisera to human $\operatorname{IgG}$, IgM, and $\operatorname{IgA}$, and it was repeated on a variety of human and rat organs as well as on liver from mouse, beef, pig, and sheep to test for species specificity. The light-chain type was examined by means of specific rabbit antisera to kappa and lambda chains. These tests were also done after absorption of the serum with excess anti-IgA, anti-K, and anti-L. Immunoelectrophoresis was done according to Scheidegger (1955) using appropriate antisera. IgA was isolated and purified on a Sepharose 2B immunoadsorbent column.

\section{RESULTS}

The fluorescent cytoplasmic pattern could be obtained on all rat organs tested with anti-IgA conjugate to a dilution of $1 / 1,280$, but was. negative with anti-IgG, anti-IgM, anti-K, and anti-L. The result became negative after absorption of the serum with anti-IgA but was unaffected by similar absomption with anti-K and anti-L.

The fluorescence pattern was of mitochondrial distribution but it differed from the mitochondrial antibodies of primary biliary cirrhosis (Doniach, 1972) and from the fluorescent cardiolipin antibody seen in syphilis (Wright and Doniach, 1971) in that it reacted only with rat tissues and gave negative results with human tissues and with all other species tested.

The antinuclear antibody reacted with several species, it was polyclonal and of IgG class. Serum immunoelectrophoresis with antihuman serum showed an arc of restricted heterogeneity corresponding with IgA (fig. 3), which was seen again with monospecific anti-IgA. Immunoelectrophoresis against anti-K and anti-L sera showed a gap in the region of the IgA band (figs. 4 and 5).

The isolated IgA was analysed by Ouchterlony gel diffusion in agar and reacted only with anti-alpha serum, giving negative results with two anti-K and two anti-L sera. This suggested absence of normal IgA molecules in the serum. The negative results with anti-K and anti-L were confirmed after reduction and alkylation of the protein. The purified alpha chains produced the same fluorescent pattern as whole serum on rat organs down to a concentration of $1 \mu \mathrm{g} / \mathrm{ml}$. These tests were again negative when anti-light chain sera were applied. Unfortunately no urine was available for testing.

\section{Discussion}

Alpha-chain disease occurs in two forms: a more common intestinal variety associated with malabsorption and diffuse intestinal lymphomas, of which 37 cases have been described (Seligmann, 1972; Frangione and Franklin, 1973), and a more unusual form affecting the lungs, of which three cases are re-

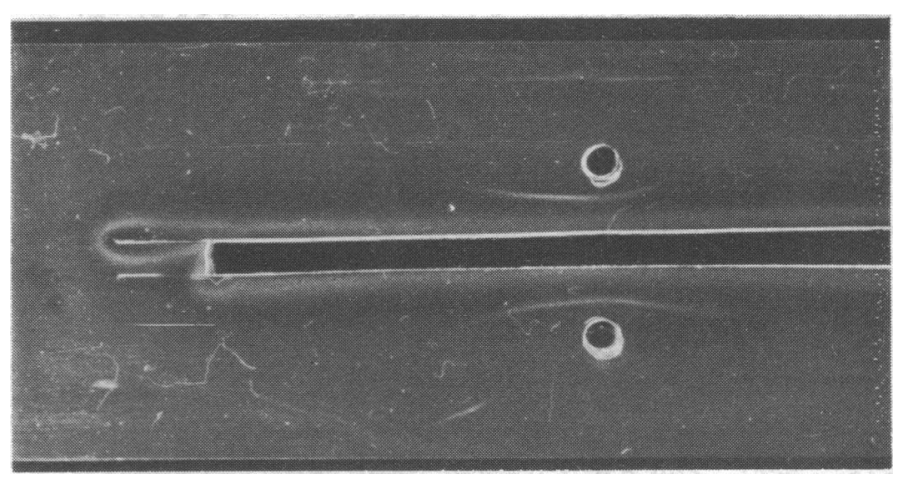

FIG. 3-Immunoelectrophoresis with antihuman IgA. Top well contains patient's serum and bottom well contains normal human serum.

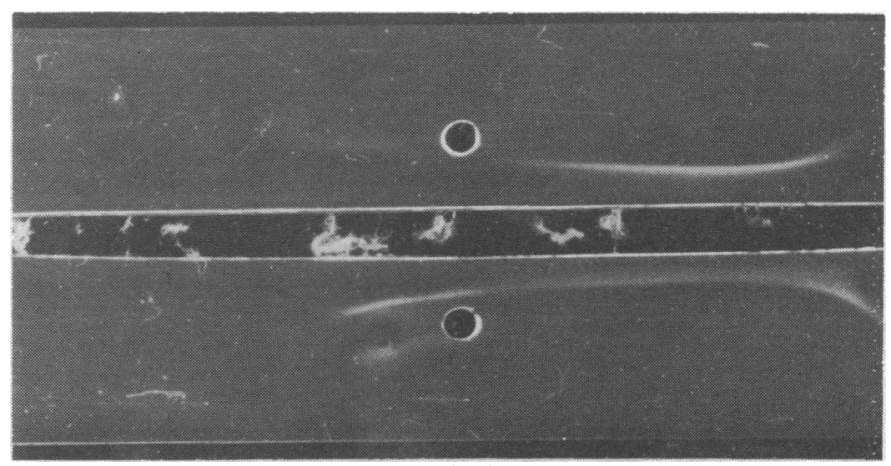

FIG. 4-Immunoelectrophoresis with antiserum to kappa chains. Top well contains patient's serum and bottom well contains normal human serum.

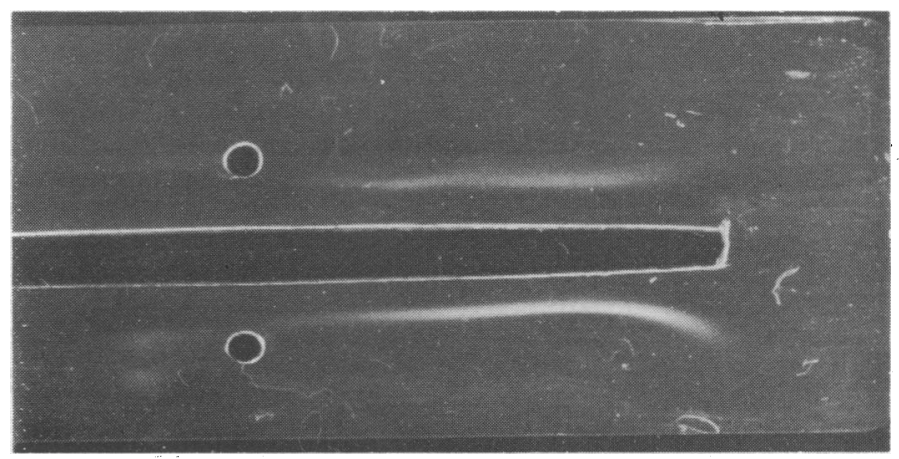

FIG. 5-Immunoelectrophoresis with antiserum to lambda chains. Top well contains patient's serum and bottom well contains normal human serum.

ponted in the literature. Two of these were in young children (Stoop et al., 1971; Faux et al., 1973) and one occurred in an adult woman (Moroz et al., 1971).

The girl described by Stoop et al. (1973) first developed attacks of dyspnoea at the age of 4 years. These attacks were independent of infections, and the chest $x$-ray picture showed a mottled appearance and enlargement of mediastinal glands. The chest $x$-ray picture was interpreted as indicating pulmonary infiltrates, but no histological evidence of this was available. The severity of dyspnoea varied from time to time. Another clinical feature was a pruritic skin rash, and biopsy showed deposits of immunoglobulins and complement at the dermal-epidermal junction. Our patient had a similar history of variable dyspnoea, mottling on chest $x$-ray picture, and enlarged mediastinal glands, and though he had an irritating rash it is difficult to say whether this is a feature of pulmonary alpha-chain disease as skin lesions are not mentioned in the other two case reports. 
The patient of Faux et al. (1973) was a 3-year-old boy with recurrent respiratory infections and otitis media from the age of 6 months. There is no mention of dyspnoea or of radiological appearances. The patient described by Moroz et al. (1971) was a woman aged 30 with a history of repeated tonsillitis since childhood. No description is given of chest $x$-rav pioture or mediastinal glands. In this case the abnormal IgA was also detected in two svmptomless relatives, and culture of the patient's tonsillar lvmphocytes showed that they were able to synthesize light chains as well as alpha-heavy chains, suggesting a familial defect of assembly. This patient's urine contained both alpha-chains and Bence Jones proteins. In the Dutch girl only a trace of alpha-chains was detected and in the boy nothing was found on seventy-fold urinary concentrations.

In heavy-chain disease generally the concentration and molecular weight of the abnormal proteins vary considerably, hence the irregular urinary excretion. Bence Jones proteinuria is usually minimal and in some cases no light chains seem to be synthesized (Seligmann et al., 1968). In both the intestinal and the pulmonary forms of alpha-chain disease the abnormal immunoglobulin is devoid of light chains and the heavy chains show varying degrees of deletion in the aminoacid sequence, concerning mainly the $\mathrm{Fd}$ portion (Frangione et al., 1971).

None of the pulmonary cases including our own showed any evidence of lymphoma. Stoop et al.'s girl developed a pharyangeal paragranuloma in which, however, no IgA-secreting cells could be shown. The disease seems to be fairly benign since three patients are alive and our patient died at 78 without any evidence of malignancy at necropsy. He had a heavy proteinuria, but unfontunately the urine was not studied since the diagnosis was not suspected during life. In the serum the IgA consisted entirely of abnormal alpha-chains, suggesting that the synthesis of normal IgA molecules was inhibited. This alpha-chain differs from those in previous cases in that it seems to have an antibody activity detected by immunofluorescence and directed against a constituent of rat mitochondria. It is usually considered that both heavy-chain and light-chain $\mathrm{N}$-terminals are needed for antibody activity, but there is another precedent in a Bence Jones protein reported by Oscerman et al. (1964) which apparently gave a cytoplasmic fluorescence on several tissues. Possibly this antibody activity represents a coss reaction with a bacterial or viral antigen. Further studies on the nature of the antigen are in progress. So far it is known that the patient's serum showed no high titres of antibodies to rubella, measles, and herpes tvpe 1 viruses, and absorption with cardiolipin (Venereal Disease Research Laboratory antigen), streptolysin $\mathrm{O}$, and staphylolysin failed to inhibit the mitochondrial fluorescence seen on rat tissues.

W/e thank Dr. G. Bull and Miss Iris Cotgrove for their helpful advice, Mr. G. Swana for his expert technical help, and Miss Hilary Fischler for preparation of the manuscript. A. F-C. is in receipt of a Wellcome Trust Felllowship. Work in the Department of Immunology is supported by the Medical Research Council and the World Health Organization.

\section{References}

Doniach, D. (1972). Progress in Clinical Immunology, 1, 45.

Faux, J. A., Crain, J. D., Rosen, F. S., and Merler, E. (1973). Clinical Immunology and Immunopathology, 1, 282.

Frangione, B., et al. (1971). Annals of New York Academy of Sciences, 190, 71 Frangione, B., and Franklin, E. C. (1973). Seminars in Haematology, 10, 53. (1971). Fournal of Clinical Investigation, 50,2726

Osserman, E. F., Takatsuki, K., and Talal, N. (1964). Seminars in Haematology, 1, 3 .

Scheidegger, J. J. (1955). International Archives of Allergy and Applied Immunology, $7,103$.

Seligmann, M., Danon, F., Hurez, D., Mihaesco, E. and Preud'homme, J. L. Science, 1968, 162, 1397

Seligmann, M. (1972). European fournal of Clinical and Biological Research, 17,349

Stoop, J. W., Ballieux, R. E., Hijmans, W., and Zegers, B. J. M. (1971) Clinical and Experimental Immunology, 9, 625.

Wright, D. J., and Doniach, D. (1971). Proceedings of the Royal Society of Medicine, 64, 519 .

\title{
Sensitivity to Rifampicin: Incidence, Mechanism, and Prevention
}

\author{
JEAN-CLAUDE PUJET, JEAN-CLAUDE HOMBERG, GUY DECROIX
}

British Medical fournal, 1974, 2, 415-418

\section{Summary}

Five out of 200 patients taking rifampicin $900 \mathrm{mg}$ twice weekly and three out of 91 patients taking rifampicin who attended an immunology clinic developed intolerance to the drug. Antibodies to rifampicin, which were found in most cases, decreased steadily after the end of treatment but were detectable for up to 16 months. The dose of rifampicin and the blood levels are predominating factors in the occurrence of reactions. Thus the dose should be reduced in patients in whom rifampicin blood levels rise abnormally. When it is

\section{Centre Medico-Chirurgical de Cambo}

JEAN-CLAUDE PUJET, M.D.

Centre Departemental de Transfusion Sanguine de Paris

JEAN-CLAUDE HOMBERG, M.D., Head of the Immunopathology Laboratory

H6 pital Saint-Antoine, 75012 Paris

GUY DECROIX, M.D., Professor of Medicine and Head of Department of Diseases of the Chest important to continue rifampicin treatment despite intolerance antibody titres within 24 hours after administration of the drug must be measured to find when they are lowest, which determines the "unreactive period," and when a further dose may be safely given.

\section{Introduction}

A combination of rifampicin $900 \mathrm{mg}$ and isoniazid $750 \mathrm{mg}$ given twice weekly seems as effective in the treatment of tuberculosis as rifampicin $600 \mathrm{mg}$ and isoniazid $450 \mathrm{mg}$ given daily (Decroix et al., 1971). A disadvantage of the twiceweekly regimen, however, is that side effects occur, which seem to be related to the intermittent use of rifampicin (Blajchman et al., 1970; Poole et al., 1971). To investigate the reasons for these adverse reactions in intermittent therapy we studied the cases of a group of patients followed up after their discharge from hospital and of another group who had been referred for immunological investigation to the Centre Départemental de Transfusion Sanguine of Paris (C.D.T.S.). This paper reponts our findings. Though these confirmed those of others, there were certain differences which we think 